\title{
A construção da docência no ensino superior a partir do conceito de experiência
}

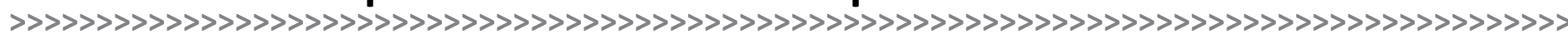

Victor Hugo Nedel Oliveira* Miriam Pires Corrêa de Lacerda** Andreia Mendes dos Santos ${ }^{* * *}$

\section{Resumo:}

A construção da identidade docente configura-se como importante processo para que os professores desempenhem a docência ligada aos seus alunos. Esta pesquisa buscou analisar as percepções de experiência de professores do ensino superior em instituições públicas e privadas em Porto Alegre. Para atingir os objetivos propostos, foi aplicado um questionário com a caracterização da amostra, a apresentação de afirmações na Escala Likert e uma pergunta aberta versando sobre as recomendações dos sujeitos para os jovens professores do ensino superior. Os resultados apontaram que os sujeitos manifestam indiferença quanto à afirmação de que a experiência seja um fator de relevância na formação do docente. Pode-se constatar que os sujeitos concordam que a identidade do professor se constrói na educação básica. Verifica-se que a maioria dos sujeitos acredita que um doutorado não seja uma exigência para ser um bom professor no nível superior.

\section{Palavras-chave:}

Experiência. Docência. Ensino superior.

\section{Abstract:}

The construction of teacher identity is an important process for teachers to perform teaching linked to their students. This research sought to analyze the perceptions of experience of higher education teachers in public and private institutions in Porto Alegre. To reach the proposed objectives, a questionnaire was applied with the characterization of the sample, the presentation of affirmations in the Likert Scale and an open question about the recommendations of the subjects for the young teachers of higher education. The results indicated that the subjects express indifference about the affirmation that the experience is a factor of relevance in the teacher training. It can be verified that the subjects agree that the identity of the teacher is built in basic education. It turns out that most subjects believe that a doctorate is not a requirement to be a good teacher at the higher level.

\section{Keywords:}

Experience. Teaching. Higher education.
* > Licenciado e Mestre em Geografia (UFRGS). Doutor em Educação (PUCRS). Professor do Departamento de Humanidades do Colégio de Aplicação da Universidade Federal do Rio Grande do Sul (UFRGS). E-mail: victor.juventudes@gmail.com.

** > Doutora em Educação (UFRGS). Membro do Grupo de Estudos e Pesquisas em Juventudes e Educação (UFRGS). E-mail: miriam.p.c.lacerda@gmail.com.

*** > Doutora em Serviço Social (PUCRS) Professora do Programa de Pós-Graduação em Educação da Pontifícia Universidade Católica do Rio Grande do Sul (PUCRS). E-mail: andreia.mendes@pucrs.br. 


\section{Introdução}

A construção da identidade docente configura-se como importante processo para que os professores desempenhem a docência de maneira a estarem ligados tanto aos seus alunos quanto ao processo pedagógico em questão. A experiência, neste contexto, adquire suma relevância, haja vista que a identidade docente se constrói de modo processual e não abruptamente a partir do dia da conclusão de uma licenciatura ou algum nível de pós-graduação.

Pesquisadores como Therrien e Loiola (2001), Marcelo (2009) e Schwartz (2010) já apresentaram importantes reflexões sobre a necessidade de pensar na experiência como componente importante na formação dos professores, tanto na educação básica quanto no ensino superior.

O conceito de experiência é extremamente rico nos mais variados contextos: social, cultural, político, filosófico e, igualmente, na educação. É necessário entender que a experiência configura-se muito além apenas do registro sobre alguma possível contagem de tempo que alguém faz algo, pois se sabe que determinados indivíduos podem realizar alguma atividade por vários anos e não construir experiências reflexivas neste meio tempo. Ou seja, o conceito de experiência está ligado principalmente às reflexões estabelecidas no decorrer dos processos de aprendizagem, sejam elas quais forem (DEWEY, 2010).

Dessa forma, unindo os conceitos de identidade docente e experiência, organizou-se o tema da presente pesquisa, que visou estudar estas relações, a partir de um espaço e tempo específicos, de acordo com o nível de profundidade exigido para a especialização cursada.

Com o tema de pesquisa da presente investigação girando em torno das questões de identidade docente e experiência, houve a necessidade de delimitação e de um recorte, para que pudesse ser enquadrado em uma pesquisa no nível de uma especialização, cuja produção final é de um artigo científico de, no máximo, doze páginas.

Assim sendo, buscou-se organizar a pesquisa para ser aplicada entre vinte e trinta professores do ensino superior que lecionem em universidades públicas ou privadas, em Porto Alegre e região metropolitana. A investigação girou em torno das percepções de experiência dos professores participantes do estudo. Sabe-se que existem diferentes visões e concepções deste conceito, portanto, a investigação buscou entender como esses professores percebem a constituição de sua identidade docente no ensino superior.

A principal justificativa para a realização da investigação foi a produção de novos conhecimentos para uma melhor interação professor-alunos em relação ao tema da docência no ensino superior no momento contemporâneo. De todas as formas, muitos benefícios podem ser encontrados a partir de um levantamento de informações básicas sobre determinado grupo de professores.

A partir do que já fora exposto, apresenta-se a seguinte pergunta de pesquisa: "Como a experiência influenciou a construção da docência de professores do ensino superior?".

O objetivo geral da pesquisa foi analisar as percepções de experiência de professores docentes no ensino superior em instituições públicas e privadas em Porto Alegre. Os objetivos específicos foram: caracterizar a amostra de pesquisa quanto aos aspectos de docência no ensino superior; verificar o grau de concordância dos participantes do estudo quanto a diferentes situações e conceitos sobre a experiência no ensino superior; e descobrir as recomendações aos jovens professores no ensino superior, dos professores participantes da investigação.

Metodologicamente, tratou-se de uma pesquisa de natureza básica, pois objetivou produzir conhecimentos novos que ao mesmo tempo sejam úteis para o avanço da ciência. A pesquisa envolve questões consideradas verdades ou interesses universais (GIL, 1999). Assim, neste tipo de pesquisa, busca-se satisfazer uma necessidade intelectual pelo conhecimento e sua meta é o saber (CERVO; BERVIAN, 2002), no caso específico, o saber sobre os conceitos de experiência e identidade docente. 
Ao mesmo tempo, do ponto de vista da abordagem do problema, configura-se como uma pesquisa qualitativa, visto que considera que há uma relação dinâmica entre o mundo real e o sujeito, isto é, um vínculo indissociável entre o mundo objetivo e a subjetividade do sujeito que não pode ser traduzido em números (COLLIS; HUSSEY, 2005), assim sendo, o instrumento de pesquisa configura-se como uma entrevista.

Do ponto de vista de seus objetivos, trata-se de uma pesquisa exploratória, pois proporciona maior proximidade com o problema, visando a torná-lo explícito ou definir hipóteses. Procura aprimorar ideias ou descobrir intuições. Possui um planejamento flexível, envolvendo, em geral, levantamento bibliográfico, entrevistas com pessoas que tiveram experiências práticas com o problema pesquisado e análise de exemplos similares. Assume as formas de pesquisas bibliográficas e estudos de caso. (GIL, 1996; DENCKER, 2000).

Em relação aos procedimentos técnicos, a investigação é um estudo de caso, já que envolve o estudo profundo e exaustivo de um ou poucos objetos, de maneira que se permita o seu amplo e detalhado conhecimento (GIL, 1999).

\section{Experiência docente: quanto mais, melhor?}

Para apresentar e analisar os dados coletados para a investigação, utiliza-se da divisão apresentada no instrumento de coleta de dados, ou seja, o questionário. Inicialmente, é realizada a apresentação da caracterização da amostra de pesquisa, através das informações como sexo, idade, tempo de docência na educação básica, tempo de docência na educação superior, área em que atua e tipo de instituição dos sujeitos. Logo após, são apresentados os graus de concordância ou discordância dos sujeitos em relação a afirmações sobre diferentes temas relacionados aos conceitos de identidade e experiência no ensino superior. Por fim, são apresentadas categorias criadas a partir das respostas em relação às recomendações dos participantes da investigação para os jovens professores do ensino superior.

\section{Caracterização da amostra}

Há uma divisão equitativa em relação ao gênero dos sujeitos da pesquisa, como se pode observar no gráfico 1 . Trata-se de $52 \%$ de participantes do sexo masculino e, consequentemente, $48 \%$ de participantes do sexo feminino. Dessa forma, não se encontraram disparidades em relação a este tocante.

\section{Gráfico 1 - Sexo dos sujeitos de pesquisa}

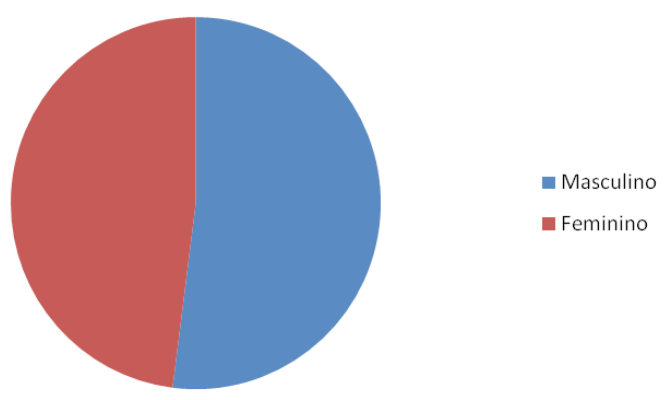

Fonte: Os autores (2019).

Sobre a idade dos sujeitos da pesquisa, a partir da observação do gráfico 2, pode-se verificar que há um visível pico de participantes com mais de 60 anos de idade (38\%), o que indica que esta maioria encontra-se em faixa etária que notadamente possui mais experiência, seja ela de vida acadêmica ou até mesmo de vida pessoal, na medida em que tais 
potencialidades também colaboram nas vivências docentes. Para além disso, localizam-se pequenas disparidades em uma faixa equitativa (20\% entre 31 e 40 anos; $18 \%$ entre 41 e 50 anos e $20 \%$ entre 51 e 60 anos) ou para menos (4\% apresentando idade entre 18 e 30 anos).

\section{Gráfico 2 - Idade dos sujeitos de pesquisa}

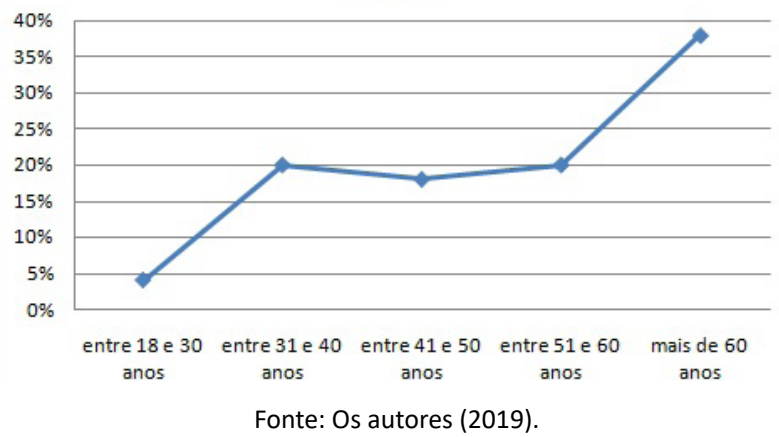

De acordo com a análise do gráfico 3, é possível constatar que $45 \%$ dos sujeitos declararam que nunca realizaram atividades de docência na educação básica, ou seja, a grande maioria dos investigados não obteve experiência na educação básica (educação infantil, ensino fundamental ou ensino médio). Por outro lado, $55 \%$ dos sujeitos afirmaram possuir tempo de docência na educação básica, sendo $10 \%$ com experiência entre 1 e 5 anos; igualmente $10 \%$ com 5 até 10 anos de docência na educação básica; $15 \%$ com tempo de 11 até 20 anos de docência neste nível e $20 \%$ com mais de 21 anos de docência na educação básica.

\section{Gráfico 3 - Tempo de docência na educação básica dos sujeitos de pesquisa}

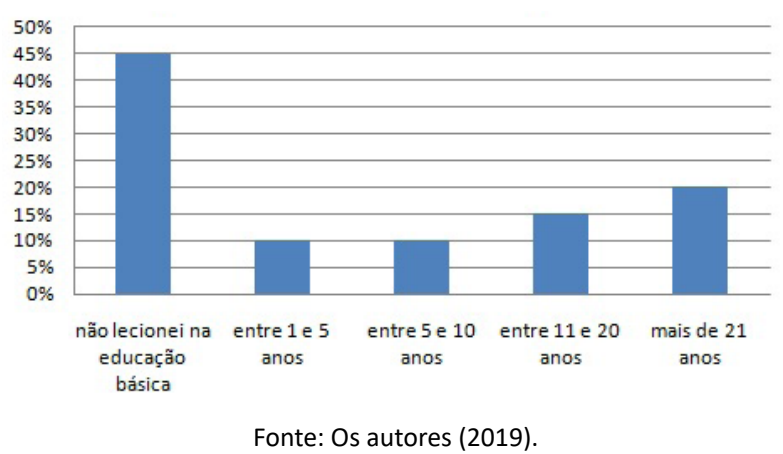

Ao analisar o gráfico 4, é possível constatar que há dois polos de concentração da experiência docente no ensino superior, dos sujeitos da pesquisa. De um lado, 25\% dos investigados afirmaram ter entre 1 e 5 anos de docência no ensino superior, ou seja, tratase de professores iniciantes neste nível de ensino. Na outra ponta, há os professores com maior tempo de experiência: $25 \%$ entre 11 e 20 anos de experiência e $35 \%$ com mais de 21 anos de experiência no ensino superior. Há uma concentração baixa na faixa intermediária entre 5 e 10 anos de experiência, com o percentual de $5 \%$. 


\section{Gráfico 4 - Tempo de docência no ensino superior dos sujeitos de pesquisa}

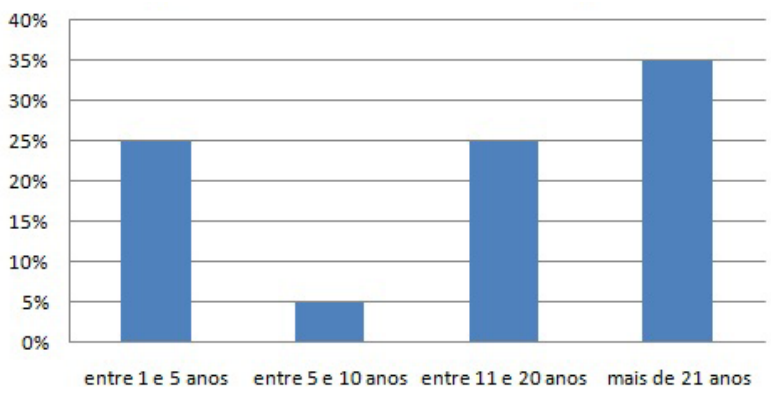

Fonte: Os autores (2019).

Quanto às áreas de atuação no ensino superior, é possível observar, no gráfico 5, que a maior parte dos sujeitos atua na área de ciências humanas (50\%), entre os cursos de Pedagogia, Sociologia, História, Geografia e Psicologia, por exemplo. Seguidos de 30\% dos sujeitos do campo das ciências biológicas (Medicina, Odontologia, Enfermagem e Biologia, por exemplo). O menor percentual concentrou-se na área das ciências exatas: $20 \%$, com sujeitos docentes dos cursos das variadas Engenharias, ou ainda das áreas de Matemática ou Física.

\section{Gráfico 5 - Áreas em que os sujeitos de pesquisa atuam no ensino superior}

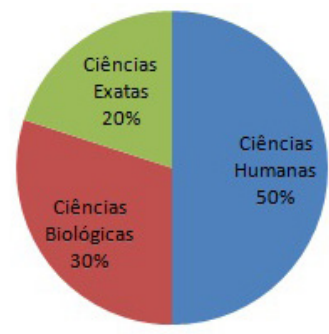

Fonte: Os autores (2019).

Pela análise do gráfico 6, é possível constatar que há certo equilíbrio entre os tipos de instituições nas quais os sujeitos trabalham, com porcentagem levemente maior para as instituições públicas. Cabe ressaltar que a investigação não objetivou, em primeiro lugar, analisar tais diferenças. Estes dados servem para que se possa construir um perfil geral da amostra dos sujeitos da pesquisa.

\section{Gráfico 6 - Tipo de instituição em que o docente trabalha}

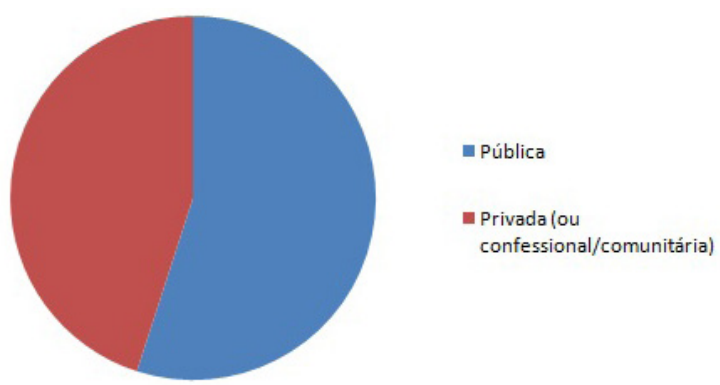

Fonte: Os autores (2019). 


\section{Concordâncias e discordâncias}

Para seguir na análise sobre as percepções de experiência de professores docentes no ensino superior em instituições públicas e privadas em Porto Alegre dos participantes da investigação, apresentam-se os resultados que dizem respeito aos graus de concordância ou discordância das seguintes afirmações: "A experiência é um fator de alta relevância na formação do professor do ensino superior"; "A identidade do professor de ensino superior se constrói na educação básica"; "Para ser um bom professor no ensino superior é necessário ter doutorado"; "Experiência não é o principal fator para ser professor no ensino superior"; e "Licenciados tendem a ser melhores professores no ensino superior".

Em relação à afirmação "A experiência é um fator de alta relevância na formação do professor do ensino superior", a partir da leitura e da interpretação do gráfico 7, é possível afirmar que $50 \%$ dos sujeitos da pesquisa estão na faixa de indiferença com a afirmação. Exatos $20 \%$ estão na faixa de discordância parcial e 30\% estão na faixa de concordância parcial. É importante destacar que não houve nem concordância nem discordância extrema em relação à afirmação. Tais percentagens demonstram que não há consenso entre os sujeitos respondentes em relação ao tema e que, em uma leitura inicial, o tema da experiência fica em suspenso, sobre sua relevância na formação dos profissionais docentes no ensino superior.

Gráfico 7 - Afirmação: “A experiência é um fator de alta relevância na formação do professor do ensino superior"

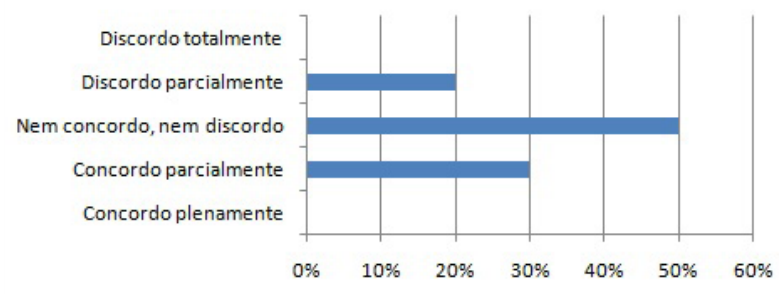

Fonte: Os autores (2019).

Já em relação à afirmação "A identidade do professor de ensino superior se constrói na educação básica” (gráfico 8), 70\% estão na faixa de concordância, 10\% estão na faixa de discordância parcial e $20 \%$ estão na faixa de indiferença em relação a mesma. A análise destes dados, em conjunto com os do gráfico anterior, coloca em voga a necessidade de pensar a construção da experiência do docente - seja no ensino superior ou em outro nível - a partir das vivências que se tem na escola básica, ou seja, não somente a posição de estudante no ensino superior ou na pós-graduação formam o professor, mas também a posição de aluno durante os mais de doze anos da educação básica formal. O ser professor é, notadamente, formado a partir do exemplo, seja este positivo ou não.

\section{Gráfico 8 - Afirmação: "A identidade do professor de ensino superior se constrói na educação básica"}

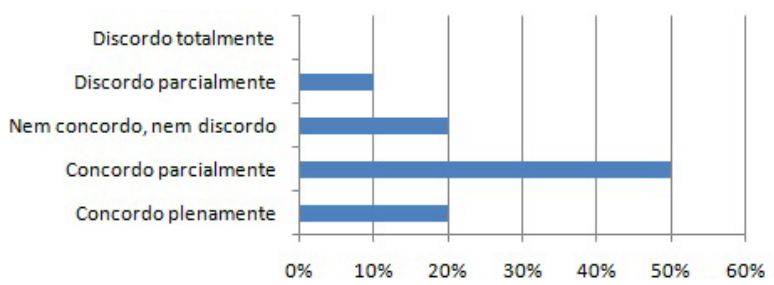

Fonte: Os autores (2019).

A afirmação "Para ser um bom professor no ensino superior é necessário ter doutorado" recebe $70 \%$ de discordância, $20 \%$ de indiferença e $10 \%$ de concordância parcial, como 
explicitado no gráfico 9. É imperativo lembrar que, de maneira geral, as instituições públicas tomam por exigência o nível de doutoramento para a maioria dos acessos aos concursos públicos e que as instituições privadas vêm investindo em um quadro docente mais qualificado e com maiores níveis de formação acadêmica. É bem verdade que o doutorado não precisa ser exatamente um pré-requisito para ser docente no ensino superior em algumas situações, mas fica claro, a partir da análise destas porcentagens, que os sujeitos expressam que a titulação não influencia, diretamente, na constituição de um bom professor, mas sim se elencam como possibilidades, a experiência, a boa vontade e o preparo de aulas para tanto.

\section{Gráfico 9 - Afirmação: “Para ser um bom professor no ensino superior é necessário ter doutorado"}

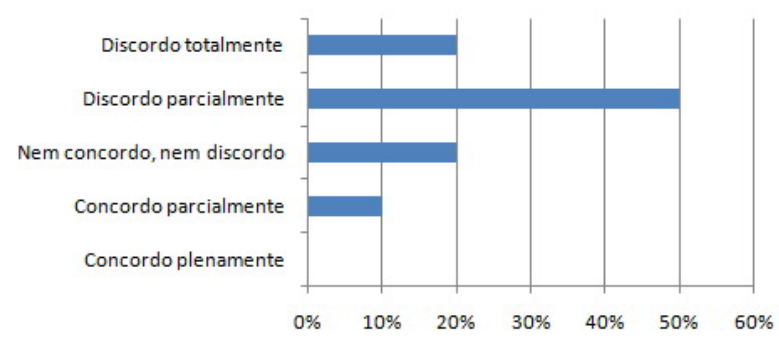

Fonte: Os autores (2019).

Em conjunto sobre os questionamentos da hipotética necessidade de titulação para docência no ensino superior, colocou-se a afirmação "Experiência não é o principal fator para ser professor no ensino superior" (gráfico 10) e, a partir de sua análise, verificou-se que não há consenso em relação ao tema, por parte dos sujeitos da pesquisa. Trata-se de $40 \%$ na faixa da discordância (plena ou parcial), 10\% na faixa de indiferença e outros 50\% na faixa de concordância (plena ou parcial). $O$ fato de não haver consenso em relação à frase apresentada indica que existem múltiplas formas de interpretar a afirmação e que também existem múltiplas formas de interpretar o conceito de experiência, como já dito em tópicos anteriores. Esta investigação utilizou o conceito de experiência baseado em Dewey (2010), que articula os conhecimentos adquiridos em determinadas situações com os conhecimentos prévios dos sujeitos e os desejos de novas aprendizagens.

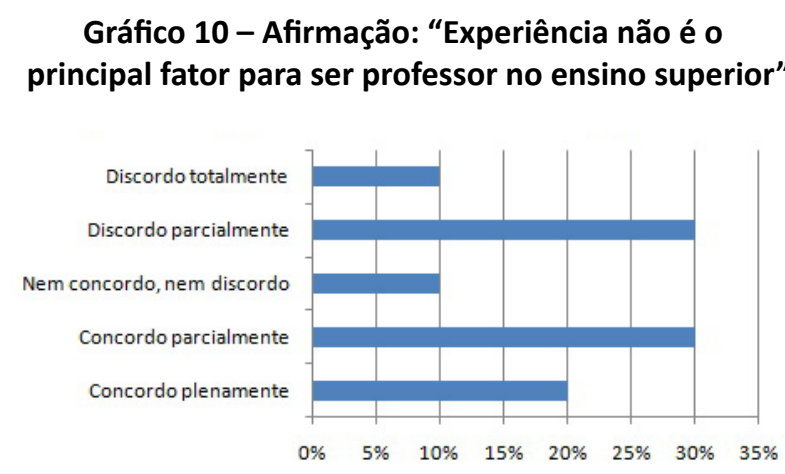

Fonte: Os autores (2019).

Ao final das análises das afirmações a partir da escala Likert, e após as constatações das afirmações e análises dos gráficos 7 ao 10, a afirmação "Licenciados tendem a ser melhores professores no ensino superior" revelou a ligação dos sujeitos com os demais tópicos apresentados. Em relação a esta afirmação (gráfico 11), a faixa de concordância girou em torno de $40 \%$, a faixa de indiferença igualmente em $40 \%$ e a faixa de discordância em torno de $20 \%$. Tal distribuição põe em debate a seguinte reflexão: em que pese os sujeitos da pesquisa reconhecem que não há a necessidade da maior titulação para ser 
um bom professor no ensino superior, uma parcela acredita que a experiência continua sendo o fator de maior relevância para melhores desempenhos neste nível.

\section{Gráfico 11 - Afirmação: "Licenciados tendem a ser melhores professores no ensino superior"}

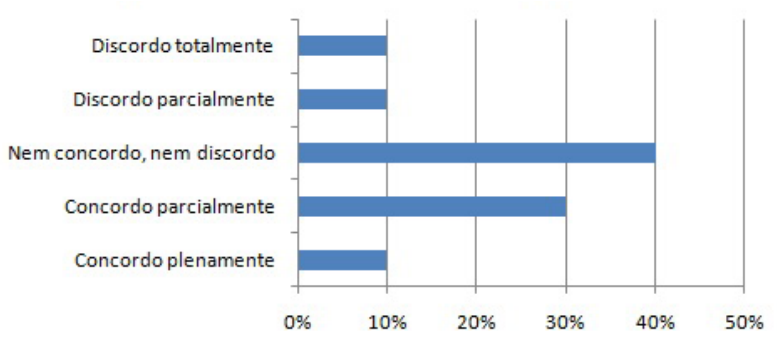

Fonte: Os autores (2019).

\section{Recomendações aos jovens professores do ensino superior}

Em relação às recomendações dos sujeitos da pesquisa para os jovens professores do ensino superior, foi realizada a seguinte questão: “Quais são as suas recomendações para os jovens professores do ensino superior?”. Foi uma questão dissertativa aberta, na qual os sujeitos podiam escrever por extenso suas repostas, ou seja, suas recomendações, a partir de suas práticas e experiências.

Com base na análise das falas dos participantes da investigação, foram elencadas quatro categorias básicas a partir das respostas escritas. São elas: recomendações em relação à prática pedagógica; recomendações em relação às questões de identidade docente; recomendações em relação ao serviço público ou iniciativa privada; e recomendações em relação às questões burocrático-administrativas.

Sobre as recomendações em relação à prática pedagógica, alguns exemplos de escritas dos sujeitos podem ser apresentados, tais como:

S1: É importante que mantenham a formalidade em suas carreiras. O professor do ensino superior é formal. (Citação oral, s.p)

S2: Não seja amigo de seus alunos. Não seja o "parceiro". Seja o professor que gosta do que faz, mas que cobra. (Citação oral, s.p)

S3: Ser professor no ensino superior é estar em constante atualização e busca pela capacitação docente. (Citação oral, s.p)

Já sobre recomendações em relação às questões de identidade docente, alguns exemplos de escritas dos sujeitos podem ser apresentados, tais como:

S4: Seja um professor inteligente, ou seja, estude sempre. O professor da graduação e da pós-graduação não para de estudar. (Citação oral, s.p)

S5: É importante que os jovens professores para o ensino superior tenham em mente que a experiência e a prática docente andam juntas. (Citação oral, s.p)

E sobre recomendações em relação ao serviço público ou iniciativa privada, notamse alguns exemplos de escritas dos sujeitos em relação ao tema, tais como: 
S6: Fazer concurso público. Nunca se sabe quando te demitirão em uma faculdade privada. (Citação oral, s.p)

S7: Na privada te pagam mais, mas na pública tens a estabilidade. São escolhas a fazer. (Citação oral, s.p)

Por fim, sobre as recomendações em relação às questões burocrático-administrativas, observam-se alguns exemplos de escritas dos sujeitos em relação ao tema, tais como:

S8: Repense suas escolhas. Hoje, trabalhamos mais com demandas administrativas e cada vez menos com a aula em si. (Citação oral, s.p)

A partir desses oito excertos das falas dos participantes da investigação, é possível observar quão ricas são suas falas e, ao mesmo tempo, as facetas das recomendações aos ingressantes nas carreiras, ou seja, constatam-se as demandas positivas, as neutras e outras negativas em relação ao investimento da carreira docente no ensino superior.

\section{Considerações finais}

Neste trabalho abordou-se a construção da docência no ensino superior a partir do conceito de experiência, através das respostas dos sujeitos, professores deste nível de ensino, em instituições públicas e privadas em Porto Alegre, RS. O principal objetivo do trabalho foi analisar as percepções de experiência de professores docentes no ensino superior em instituições públicas e privadas localizadas em Porto Alegre. Para atingir este objetivo, aplicou-se um questionário dividido em três partes principais, que possibilitaram atingir os objetivos específicos da investigação.

Ao caracterizar a amostra de pesquisa, foi possível conhecer, ainda que superficialmente, os sujeitos da investigação, a partir de informações como sexo, idade, tempo de docência na educação básica, tempo de docência no ensino superior, área de trabalho no ensino superior e tipo de instituição de trabalho (pública ou privada). A caracterização da amostra de uma pesquisa permite ao pesquisador um reconhecimento do campo e dos sujeitos, de maneira a identificar possíveis futuras relações com os demais campos do instrumento de coleta de dados, o questionário, no caso.

Ao apresentar afirmações sobre os temas de identidade e experiência docente no ensino superior e solicitar aos sujeitos da pesquisa seu grau de concordância, indiferença ou discordância da pesquisa, interessantes análises puderam ser feitas: a maior parte dos inquiridos nem concorda nem discorda, quando postos frente à afirmação "A experiência é um fator de alta relevância na formação do professor do ensino superior”; a maior parte desses sujeitos concorda que a identidade do professor de ensino superior se constrói na educação básica; discordam, ainda em maioria, que para ser um bom professor no ensino superior é necessário ter doutorado; por fim, há um equilíbrio tanto de concordância, discordância ou indiferença em relação às afirmações "experiência não é o principal fator para ser professor no ensino superior" e "licenciados tendem a ser melhores professores no ensino superior", o que justamente corrobora com a integralidade do questionário e das demais análises e discussões realizadas.

Ao perguntar aos sujeitos da pesquisa "Quais são as suas recomendações para os jovens professores do ensino superior?” quatro categorias foram elencadas a partir da análise das respostas: recomendações em relação à prática pedagógica; recomendações em relação às questões de identidade docente; recomendações em relação ao serviço público ou iniciativa privada; e recomendações em relação às questões burocrático-administrativas. 
Nesse sentido, constata-se um ponto de queixas em relação ao trabalho docente no ensino superior e outro de esperança, que não deriva do verbo esperar, mas sim deriva do verbo esperançar, ou seja, não se espera que os jovens professores queiram ou desejem algo, mas sim se promete uma melhor docência, na esperança de que novas oportunidades e novos espaços/tempos de trabalho possam surgir.

Conhecer a construção da docência no ensino superior a partir do conceito de experiência não se configura, então, como algo importante apenas para os professores do ensino superior, mas sim para todo e qualquer professor, já que as bagagens trazidas pelos sujeitos da pesquisa devem sempre ser utilizadas como referência para partir da base já existente nos alunos/professores e, com isso, possibilitar a exploração de novos horizontes, um milagre moderno que a educação como um todo vem realizando com todo o empenho e dedicação possíveis.

\section{Referências}

CERVO, Amado L.; BERVIAN, Pedro A. Metodologia científica. 5. ed. São Paulo: Prentice Hall, 2002.

COLLIS, Jill; HUSSEY, Roger. Pesquisa em administração: um guia prático para alunos de graduação e pós-graduação. 2. ed. Porto Alegre: Bookman, 2005.

DENCKER, Ada de Freitas M. Métodos e técnicas de pesquisa em turismo. 4. ed. São Paulo: Futura, 2000.

DEWEY, John. Experiência e Educação. Tradução de Renata Gaspar. Petrópolis: Vozes, 2010.

GIL, Antônio C. Como elaborar projetos de pesquisa. 3. ed. São Paulo: Atlas, 1996.

GIL, Antônio C. Métodos e técnicas em pesquisa social. 5. ed. São Paulo: Atlas, 1999.

MARCELO, Carlos. Desenvolvimento Profissional Docente: passado e futuro. Sísifo. Revista de Ciências da Educação, v. 08, p. 7-22, 2009.

SCHWARTZ, Yves. A experiência é formadora? Revista Educação e Realidade. v. 35. n. 1, p. 35-48. jan./abr., 2010.

THERRIEN, Jacques; LOIOLA, Francisco Antônio. Experiência e competência no ensino: pistas de reflexões sobre a natureza do saber-ensinar na perspectiva da ergonomia do trabalho docente. Revista Educação \& Sociedade, ano XXII, n. 74, abr. 2001. 